\title{
Effects of Virtual Reality Exercise Program on Balance in Multiple Sclerosis Patients
}

\author{
Geun-Ho Lee \\ Department of Neurology, College of Medicine, Dankook University, Cheonan, Korea
}

Purpose: This study was conducted in order to investigate the effectiveness of an 8-week virtual reality exercise program designed around the Nintendo Wii (Wii), in improving balance among patients with Multiple Sclerosis (MS).

Methods: The study included 16 patients with MS (10 female, 6 male) who were assigned randomly to experimental $(n=8)$ or control group $(\mathrm{n}=8)$. Experimental group performed three 40-minute Wii balance-training sessions per week, for 8 weeks. The control group did not perform any of the training programs. A computerized dynamic posturography (Sensory Organizing Test, SOT) was used to evaluate all patients at baseline and at the end of the treatment protocol. Statistical significance was tested in between the patients before and after treatment by t-test.

Results: After 24 training sessions, SOT showed significant difference on condition 5, 6, and vestibular ratios within the experimental group from baseline to post-intervention. By contrast, no significant difference was observed within the control groups.

Conclusion: These findings demonstrated that the virtual reality training program could improve the outcomes in terms of balance in the MS population. Long term follow ups and the development of more efficient virtual reality training programs are needed.

Keywords: Balance, Multiple Sclerosis, Posture, Virtual reality exposure therapy

\section{서 론}

다발경화증(Multiple Sclerosis)은 신경축삭을 둘러싸고 있는 말이집 (myelin sheath)의 파괴로 인해 초래되는 중추신경계의 대표적인 탈수 초성 질환의 하나로써 다양한 형태의 장애를 동반한다. 중추신경계 의 백질 전체에 산재된 반흔을 나타내는 탈수초화된 병변은 중추신 경계 어디에든지 나타날 수 있지만 특히 대뇌의 뇌실 주변영역, 소뇌 각, 뇌뿌리, 척수후기둥 등에 자주 생기며 증상은 환자 개개인에 따라 서 상당히 다양하게 나타난다. 병리학적으로 말이집 막의 염증과 파 괴가 있고 이로 인하여 신경의 전달에 장애가 발생하여 신경세포는 쉽게 피로하게 된다. 말이집은 최후에는 신경교세포에 의해 생성된 섬유성 반흔에 의해 대치되는데 이 경화성 반흔의 정도에 따라서 질 병의 회복과 악화의 변화를 초래한다. 주요한 증상으로는 마비, 감각 장애, 경직, 균형 조절능력 저하 및 피로와 우울증 등이 있다. 20 대 초 반에서 40 대의 젊은 연령층에서 주로 발병하여 장기간 진행하므로
장애가 매우 큰 희귀난치성 질환이다. 2000년부터 2005년까지 6년간 우리나라의 MS의 유병률은 10 만 명당 3.5 명이었다. 성별로 보면 남성 은 10 만 명당 3.1 명, 여성은 10 만 명당 3.9 명이었으며, 유병률의 남녀비 는 1.26 이었다. ${ }^{3}$

균형능력 장애(balance disorder)는 MS의 급성기에서 $20 \%$ 에서 나타 나며 만성기에는 $80 \%$ 를 차지하므로 가장 흔한 운동장애 증상의 하 나이다. ${ }^{4}$ 균형 능력 장애는 MS 환자의 낙상의 주 원인이며, ${ }^{5}$ 연령과 장 애 정도가 증가할수록 심해져서 2-6개월에 52-63\%의 비율로 낙상이 일어난다고 하므로 환자가 서거나 일상 생활하는 데에 어려움을 초 래함은 물론 정신건강과 삶의 질을 크게 저하시킨다. ${ }^{-7}$ 균형이상 및 실 조증의 치료를 위한 운동치료로는 근위부 근육의 자세안정성을 강 화하는 운동치료 및 조절된 가동성 운동을 적용한 물리치료 등이 시 행되고 있으며 점진적 저항 운동치료(progressive resistance exercise) 등 이 도움이 된다고 보고되고 있다. 그러나 이러한 물리 치료를 수행하 려면 물리치료사의 지속적이고 전문적인 지도가 항상 필요하며 MS
Received January 15, 2015 Received February 9, 2015

Accepted February 9, 2015

Corresponding author Geun-Ho Lee

E-mail dneuro@hotmail.com

- The present research was conducted by the research fund of Dankook University in 2014.
Copylight $(02015$ The Korean Society of Physical Therapy

This is an Open Access article distribute under the terms of the Creative Commons Attribution Non-commercial License (Http:// creativecommons.org/license/by-nc/3.0.) which permits unrestricted non-commercial use, distribution, and reproduction in any medium, provided the original work is properly cited. 
환자들의 고질적인 정신적인 문제인 피로감과 우울증 때문에 동기유 발의 결핍 등으로 연습에 제약이 많이 따르고 중도에 포기하는 비율 이 많은 실정이다. ${ }^{8}$ 그러므로 환자가 공간적 및 비용 문제에 비교적 구 애 받지 않으면서 흥미를 잃지 않고 치료사와 좋은 관계를 유지하면 서 병원 및 가정에서도 쉽게 따라 할 수 있는 치료운동 프로그램이 개발될 필요가 있다.

최근 과학 기술과 컴퓨터 프로그램의 발달로 가상현실(virtual reality)을 이용한 운동 및 재활 중재법이 의학에 도입되고 있다.9 가상현 실의 정의는 체험자가 실제와 비슷한 경험을 하도록 컴퓨터를 이용 하여 만든 환경으로써, 다양한 피드백을 통하여 현실감을 제공하는 기술이 특징인 상호작용 시뮬레이션(interactive simulation)을 말한 다..$^{10}$ 사용자는 가상현실 속에서 게임 같은 정해진 과제를 수행하면 서 물체를 조작하는 동시에 시각, 청각 등 여러 감각을 통한 다양한 되먹임을 주고 받는 상호 작용으로 실제와 같은 것처럼 효과적으로 자신의 움직임을 조절할 수 있다.1" 가상현실을 치료에 적용하면 환자 는 능동적으로 즐기면서 과제를 수행할 수 있고, 치료에 대한 동기와 흥미가 유발될 수 있으므로, 뇌신경 질환 및 뇌손상 환자의 재활 운 동에 가상현실을 적용한 프로그램이 소개되어 연구되고 있다. ${ }^{12}$

그러나 이러한 장점에도 불구하고 이전까지의 가상현실 시스템은 복잡한 시스템을 갖추기 위해서 비용이 많이 들고, 대형장비라는 제 한성 때문에 임상적으로 환자들에게 널리 보급될 수 없었다. ${ }^{13}$ 최근 개인용 게임기로 개발되어 상업적으로 판매되고 있는 닌텐도 위 게 임기(Wii, Nintendo Inc., Kyoto, Japan)는 비디오 게임 콘솔이면서 가상 현실 시스템 구현 방식이 텔레비전 모니터를 통하는 간단한 방식이어 서 가격이 저렴하고 소형 장비로써 병원이나 가정에서 설치나 이동이 용이하다. 이 게임기는 사용자가 착용한 운동 감지 시스템을 통해 화 면에 나타난 자기의 아바타와 상호 작용하기 위해 무선컨트롤러를 사용하여 제어하는 방식이다. 컨트롤러에는 프로그램을 실행함에 있어서 방향과 속도를 인식할 수 있도록 가속도 변화에 반응하는 가 속도 감지센서가 부착되어 있다.14

이 게임기로 Wii Fit 게임들을 할 때에 사용되는 Wii balance board (위보드)는 사용자가 두 발로 딛고 서는 균형발판으로서 무게중심의 운동에서 정보를 모아 들이고 모니터 상의 가상환경 움직임에 반영 시킨다. 동시에 모니터를 보는 사용자의 시각에 되먹이기로 돌아와서 사용자는 자신의 운동을 조절할 수 있게 되는 과정을 거치므로 위보 드는 자세조절 능력의 측정 및 훈련에 도움이 된다고 한다. ${ }^{15}$ 가상현 실을 활용한 대표적인 일례이면서도 종래의 가상현실기구들보다 훨 씬 간편하고 비용이 저렴하여 쉽게 보급이 가능한 $\mathrm{Wii}$ 는 환자들에게 흥미를 유발할 수 있으며, 게임결과로 분발을 촉진하여 운동학습의 효과를 증가시킬 수 있다. ${ }^{16}$

국내에서 $\mathrm{Wii}$ 를 이용한 연구는 뇌졸중 환자, ${ }^{17}$ 척수손상 환자, ${ }^{18}$ 파
킨슨병 환자 ${ }^{19}$ 및 노인여성인구 20 를 대상으로 상지기능과 시지각 기 능 또는 하지 근력 등의 변화에 관한 연구가 있었으나 $\mathrm{MS}$ 환자의 낙 상 위험과 관련된 균형능력 장애에 Wii 운동프로그램이 미치는 영향 에 관한 연구는 없었다. 또한 가상현실을 활용한 운동프로그램의 효 과에 대한 이제까지의 연구는 주관적인 설문조사나 행동 위주의 계 측 위주였고 전산화로 정량화된 계측의 보고는 드문 실정이었다. 본 연구의 목적은, $\mathrm{MS}$ 환자들에게 가상현실 체험형 게임인 $\mathrm{Wii}$ 를 활용 한 운동치료를 시행한 후에 그렇지 않은 대조군에 비해서 자세조절 능력이 향상되는 효과가 있을 것이라는 가설이 유효한지를 정량적으 로 증명해보고자 하는 것이었다. 이를 위해서 정량화 도구인 동적 자 세측정기검사를 시행하여 평형점수를 구한 후 실험 전 후를 비교하 는 전향성 대조시험을 수행하였다.

\section{연구방법}

\section{1. 연구대상}

경기 남부 및 충남의 농촌에 거주하면서 $\mathrm{D}$ 대학병원 신경과 외래를 방 문한 후 MS로 진단되어 약물 치료를 받는 중인 환자들 중에서 자세 불안정이 뚜렷한 환자들을 대상으로 전향적 무작위 연구를 시행하 였다. 본 연구에 대하여 동의한 환자를 대상으로 면담하고 병원기록 을 조사하여 발병연령, 이환기간과 과거 병력을 확인하였고, 신경계진 찰을 통하여 환자의 장애 단계를 평가했으며 그 척도는 EDSS (Expanded version of Disability Status Scale)를 사용하였다.21 연구대상환자 의 포함 기준은 나이 20세 이상 60 세 이하, McDonald 진단기준에 따 른 MS로 확진 받은 지 2년 이상 지났을 것, 최근 6 개월간 임상적으로 안정되어있을 것, 소뇌 및 그 연결 계통에서 탈수초화가 있어서 균형 에 장애가 생겼을 것, $\mathrm{EDSS}$ 점수 3 에서 5 사이, 자력보행이 가능할 것, 간이정신상태검사에서 인지장애가 없을 것, 시력 장애가 없을 것 등 이었다. 제외기준은 MS 이외의 균형장애를 초래할 다른 질환이 있거 나, 실험 시작 1 달 전 이내에 증상의 급작스런 악화가 있는 경우 및 실 험 시작 및 수행 기간 중에 스테로이드 치료를 받은 경우로 하였다.

환자들은 실험에 참가하기 전에 연구 목적과 방법에 대하여 충분 히 설명하고 동의를 구하였고, 자발적으로 실험에 참여하는 자를 선 정하였다. 실험군 8 명과 대조군 8 명을 무작위로 배치하여 연구를 진 행하였으며 대조군의 경우 연령, 나이, 질병 이환기간 및 증상의 심한 정도와 운동습관 등에서 실험군과 조건이 비슷한 환자로서, 운동처 방을 하지 않는 신경과 의사에게 진료 받고 있는 환자들 가운데에서 배치되었다. 실험군은 $\mathrm{Wii}$ 운동 이외의 다른 운동치료 프로그램에는 참가하지 않도록 하였으며, 대조군은 어떠한 중재도 하지 않았다. 대 조군에 참여한 대상자는 실험군이 처치 받는 내용을 모르게 하였다. 모든 대상환자들의 균형의 평가는 병원에서 5 년 이상의 경력을 가지 
고 있는 물리치료사와 신경과 전문의가 실시하였으며, 평가자는 어떠 한 목적으로 평가가 수행되는지 모르게 하였다.

\section{2. 실험방법}

\section{1) 가상현실 운동프로그램}

가상현실 운동프로그램은 일본 Nintendo사에서 제작한 Wii-Fit과 Wii Sports 소프트웨어(Nintendo Inc., Kyoto, Japan)를 사용하였다. Wii Fit 게임에 포함된 Wii 보드 밸런스 시스템은 압력센서가 있는 균형발 판 위에 참여자가 올라서면 화면에 아바타(Mii)가 나타나 참여자의 움직임을 따라 하고 이는 참여자에게 시각적, 청각적 피드백을 제공 할 뿐 아니라 위 리모트 컨트롤러(Wii Remote Controller)를 통해 다양 한 움직임에 대한 진동반응을 피드백으로 제공한다. 균형발판의 센 서는 별도 보정 없이 공장 출시 그대로를 사용하였다. ${ }^{15}$

한 세션에 40 분의 시간이 소요되는 프로그램을 개인운동으로 주 3 회 시행하였다. 1 주에 120 분간 수행하는 운동으로써 총 8 주간 프로 그램을 시행하였다(총 24회 운동 세션). 각 세션에서는 Wii Fit 밸런스 게임을 균형발판을 사용하여 30 분 동안 운동하고 Wii Sports 게임(골 프 또는 볼링)을 10 분 운동하였다. 본 연구에 사용된 밸런스 게임에 대한 설명은 다음과 같다.

(1) 헤딩(Soccer Heading): 참여자는 모니터 상에서 자기에게 연속 으로 날라오는 축구공들을 헤딩해내기 위해서 균형발판 위에 서 신체중심을 좌우로 이동시킨다. 제한시간이 지나면 끝난다.

(2) 데구르르 구슬판(Table Tilt): 모니터에 나타난 테이블 위에 구슬 들이 있고 그 구슬들을 테이블을 기울여서 구멍 속에 굴려 넣 기 위해서 참여자는 신체중심을 전후 좌우로 기울인다.

(3) 펭귄 시소(Penguin Slide): 빙하 위에 있는 펭귄을 앞뒤로 미끄러 뜨려서 물고기를 잡게 하려면 참여자는 무게중심을 좌우로 기 울인다. 더 잽싸게 기울일수록 펭귄이 잡는 물고기 점수가 높아 진다.

(4) 밸런스 스키(Ski Slalom): 참여자는 스키 경기 코스에서 각 게이 트들을 지나기 위해서 신체중심을 좌우로 기울여야 한다.

(5) 외줄타기(Tightrope Tension): 참여자는 외줄을 건너가야 하고 장애물을 뛰어넘기 위해서 제 자리에서 걷거나 다리를 뻗는다.

(6) 밸런스 스노보드(Snowboard Slalom): 균형판의 양 가장자리에 다리를 두고 서서 신체중심을 앞 뒤로 기울여서 모니터 상의 스 노보드 경주 코스를 지쳐간다. 좌우로 기울일 때마다 속도가 더 빨라진다.

(7) 스키점프(Ski Jump): 스키점프를 하고 공중에서 날면서 균형 잡 힌 착지를 위해서 참여자는 균형판 위에서 몸을 적절히 구부리 거나 신체중심을 앞뒤로 기울여야한다.
스포츠 게임은 실시할 때 리모컨을 손에 쥐게 하고 실제 스포츠 동 작과 같은 동작들을 수행하게 하였다. 게임이 진행되는 동안에 치료 사가 근접 감시하여 안전사고를 대비하였다.

실험군은 Wii 운동 이외의 다른 운동치료 프로그램에는 참가하지 않도록 하였으며, 대조군은 어떠한 중재도 하지 않았다. 참여자에게 는 진행상황과 점수를 적는 수첩이 주어졌고, 각각의 운동치료 시행 여부, 시행 후 운동시간과 부작용이나 증상의 악화 유무 및 애로점 등을 기록하여 치료자에게 보고하도록 하였다. MS 환자의 균형의 평 가는 5 년 이상의 경력을 가지고 있는 신경과 전문의와 운동사가 직접 하였으며, 평가자는 어떠한 목적으로 평가가 수행되는지 모르게 하 였다.

\section{3. 측정도구 및 측정방법}

\section{1) 동적자세측정기}

본 연구에 사용된 동적자세측정기(Computerized dynamic posturography, CDP)는 Nashner에 의하여 1986년부터 상업화된 Equitest system (NeuroCom International Inc., Clackamas, OR, USA)이다. 이 검사 장비는 유동성의 시야장치(visual surround), 발판(platform) 및 컴퓨터 장치로 구성되어 있다. 발판은 전후 방향 및 발가락 쳐들기(toe-up), 발 가락 숙이기(toe-down) 방향으로 움직일 수 있도록 되어 있고, 시야장 치는 따로 움직여서 피검사자에게 시야의 혼동을 주거나 발판의 움 직임과 같이 동작됨으로써 피검사자의 시각에 혼란을 줄 수 있게 되 어있다.22

\section{2) 감각구성검사}

동적자세측정기로 감각계를 평가하는 감각구성검사(sensory organization test, SOT)는 피검사자의 체성감각을 선택적으로 자극하기 위 해 발판을 움직이거나, 시각계의 선택적 자극을 위해서 눈을 뜨거나 혹은 감거나, 시야 배경을 움직이는 등 동요에 따른 혼동된 시각(sway referenced vision)을 주는 조건들을 조합하여 여섯 가지 검사로 구성 된다. 발판 위에 올라선 직립자세에서 각 검사에서 1 회에 20 초씩 3 회 를 실시하여 평균을 낸 평형점수(equilibrium score)를 구한다. 평형점 수는 앞뒤 방향에서 발목관절을 중심으로 평형이 유지될 수 있는 최 대 한계점인 약 $12.5^{\circ}$ 를 넘을 때의 동요를 0 점으로 설정하고, 완전한 평형이 유지되고 동요가 없는 상태를 100 점으로 하여 환산한 점수이 다. 평형점수의 계산식은 다음과 같다.

$$
\text { 평형점수 }=\frac{1-\text { 동요의 폭 }}{\text { 전후방 한계 }} \times 100
$$

조건 1,2 및 3 은 고정된 발판 위에서 각각 정상시각, 눈을 감았을 때 및 배경이 동요를 따라 움직여서 혼동을 주는 시각 등의 조건들로 검 사하여, 피검사자의 균형의 유지에 정상 시각이 필요한지와 부적절 


\section{I.}

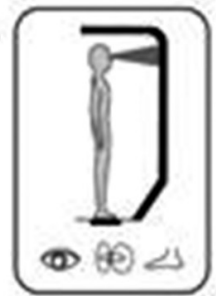

2.
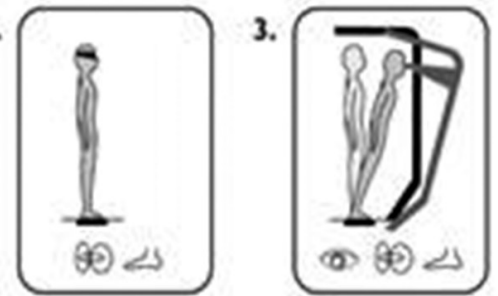

4.

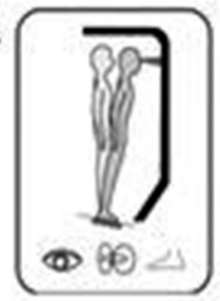

5.

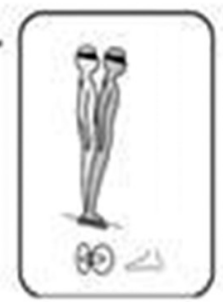

6.

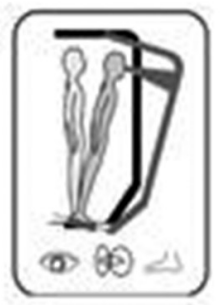

Figure 1. Sensory organization test.

한 시각을 뇌신경이 억제를 할 수 있는지를 검사한다. 조건 4,5 및 6 은 위의 세 조건에다가 피검사자가 동요하는 정도에 따라 움직이는 발판, 즉 체성감각의 혼동(sway referenced somatosensation) 상황을 추 가하여 검사하는 것이다(Figure 1).

이 조건들을 비교하여 아래와 같은 감각분석(sensory analysis)을 할 수 있다. 체성감각비(somatosensory ratio, $\mathrm{SOM}$ )는 시각의 도움이 사라 지면 신체동요가 얼마나 증가하는지를 본다. 조건 2 의 평형점수를 조 건 1 의 평형점수로 나눈 값이다. 시각비(visual ratio, VIS)는 체성감각 이 배제된 체 시각이 효과적으로 이용되는지를 알 수 있다. 조건 4 의 평형점수를 조건 1 의 평형점수로 나눈 값이다. 전정비(vestibular ratio, VEST)는 시각과 체성감각이 배제된 체 전정기능만 정상적인가를 알 아보는 것이다. 조건 5 의 평형점수를 조건 1 의 평형점수로 나눈 값이 다. 시각선호(visual preference, PREF)는 부정확한 시각정보를 뇌신경 이 억제하고 신체의 균형을 유지시킬 수 있는지를 알아보는 것이다. 조건 3 과 조건 6 의 평형점수를 더한 값을 조건 2 와 조건 5 의 평형점수 를 더한 값으로 나누어서 구한다. ${ }^{22}$

\section{4. 통계방법}

실험 결과의 값은 SPSS ver. 12.0 for Windows 통계 프로그램(SPSS Inc., Chicago, IL, USA)으로 분석하였다. 모든 자료는 Shapiro-Wilk 검정 방 법을 사용하여 정규 분포함을 확인하였다. 측정된 모든 변인에 대하 여 평균과 표준오차를 산출하고, 실험군 및 대조군 각 그룹 안에서의 가상현실 실험 전과 후의 유의성 검정은 대응표본 $\mathrm{t}$ 검정(paired t-test) 을 사용하였고, 각 군 간의 실험 전, 후 변화량차이에 대한 유의성 검 정은 독립표본 $\mathrm{t}$ 검정(independent t-test)을 사용하였다. 유의수준은 $\mathrm{p}<0.05$ 로 하였다.
Table 1. Demographic characteristics of subjects

$(n=16)$

\begin{tabular}{|c|c|c|c|c|}
\hline \multicolumn{2}{|c|}{ Variables } & $\begin{array}{l}\text { Experimental group } \\
\qquad(n=8)\end{array}$ & $\begin{array}{l}\text { Control group } \\
\qquad(n=8)\end{array}$ & $\mathrm{p}$-value \\
\hline \multicolumn{2}{|c|}{ Age (year) } & $39.2 \pm 7.2$ & $41.5 \pm 8.3$ & 0.063 \\
\hline \multicolumn{2}{|c|}{ Sex (women/men) } & $5 / 3$ & $5 / 3$ & 0.999 \\
\hline \multicolumn{2}{|c|}{ Years since diagnosis } & $9.52 \pm 5.2$ & $10.12 \pm 5.7$ & 0.155 \\
\hline \multirow[t]{3}{*}{ MS type } & PP & $25.0 \%(n=2)$ & $12.5 \%(n=1)$ & \\
\hline & $\mathrm{RR}$ & $62.5 \%(n=5)$ & $62.5 \%(n=5)$ & \\
\hline & SP & $12.5 \%(n=1)$ & $25.0 \%(n=2)$ & \\
\hline \multirow[t]{3}{*}{ EDSS } & Score 3 & $12.5 \%(n=1)$ & $12.5 \%(n=1)$ & \\
\hline & Score 4 & $75.0 \%(n=6)$ & $75.0 \%(n=6)$ & \\
\hline & Score 5 & $12.5 \%(n=1)$ & $12.5 \%(n=1)$ & \\
\hline
\end{tabular}

Values are presented as mean \pm standard deviation.

MS, Multiple sclerosis; PP, Primary progressive; RR, Relapsing remitting; SP, Secondary progressive.

결 과

\section{1. 연구대상자의 인구학적 특성}

연구에 참여한 대상자는 총 16 명으로 대상자의 인구학적 특성은 Table 1 과 같다. 평균 나이는 실험군은 $39.2 \pm 7.2$ 세, 대조군은 $41.5 \pm 8.3$ 세 였으며, 이환기간, MS type 및 EDSS 척도는 실험시작 시점에서 두 집 단 사이의 특성이 통계학적으로 유의한 차이가 없었다.

\section{SOT 검사의 변화}

실험군과 대조군 모두 실험 시작 시점에서의 SOT 점수는 유의한 차 이가 없었다. 실험종료 시에는 조건 5 와 6 에서 실험군의 점수가 실험 후에 실험 전보다 유의하게 증가되었음을 보였다 $(\mathrm{p}<0.05)$. 대조군은 실험 전과 실험 후의 점수가 유의한 변화가 없었다. 실험 전과 후의 집 단 간 변화량의 차이를 비교한 결과 실험군이 대조군보다 조건 5 와 6 에서 유의하게 증가한 것으로 나타났다(Table 2).

실험 시작 시점에서 감각비는 실험군과 대조군 사이에 유의한 차 이가 없었다. 실험기간 종료 시 실험군은 전정비 항목의 점수가 운동 전보다 유의하게 향상되었다 $(\mathrm{p}<0.05)$. 대조군은 감각비가 실험종료 후에 유의한 변화가 없었다. 실험군의 전정비의 증가량이 대조군의 그것보다 유의한 차이를 보였다 $(\mathrm{p}<0.05)$ (Table 3).

\section{고 찰}

본 연구의 목적은 MS 환자들의 균형에 대한 가상현실프로그램의 효 과를 정량적인 검사를 통하여 밝혀보려는 것으로써, 이전까지의 연 구들은 균형능력의 척도로서 주관적인 설문조사 또는 한쪽 다리 들 고 서있기 등 비정량적인 계측방법을 주로 사용하였기 때문이었다. 본 연구에서는MS 환자들에게 동적자세측정기를 활용한 정량적인 
Table 2. Equilibrium scores for the sensory organization test (SOT) before and after training

\begin{tabular}{|c|c|c|c|c|c|c|}
\hline \multirow[b]{2}{*}{ Condition (score) } & \multicolumn{2}{|c|}{ Experimental group } & \multicolumn{2}{|c|}{ Control group } & \multicolumn{2}{|c|}{ Change values } \\
\hline & Pre-test & Post-test & Pre-test & Post-test & $\begin{array}{c}\text { EX } \\
\text { Post-pre }\end{array}$ & $\begin{array}{c}\text { CONT } \\
\text { Post-pre }\end{array}$ \\
\hline SOT-1 & $92.2 \pm 3.1$ & $91.5 \pm 2.7$ & $91.5 \pm 3.2$ & $90.4 \pm 3.4$ & $-0.7 \pm 2.9$ & $-1.1 \pm 3.1$ \\
\hline SOT-2 & $87.5 \pm 3.5$ & $88.7 \pm 3.5$ & $88.9 \pm 3.3$ & $89.3 \pm 4.1$ & $1.2 \pm 2.1$ & $0.4 \pm 3.5$ \\
\hline SOT-3 & $87.1 \pm 3.7$ & $88.5 \pm 3.4$ & $87.2 \pm 3.8$ & $88.2 \pm 3.7$ & $1.4 \pm 2.5$ & $1.0 \pm 2.7$ \\
\hline SOT-4 & $68.5 \pm 8.1$ & $70.4 \pm 6.3$ & $70.2 \pm 4.5$ & $68.2 \pm 4.2$ & $1.9 \pm 2.8$ & $-2.0 \pm 2.9$ \\
\hline SOT-5 & $43.2 \pm 6.8$ & $53.2 \pm 6.7^{*}$ & $45.3 \pm 8.3$ & $39.9 \pm 9.2$ & $10.0 \pm 2.3^{*}$ & $-5.4 \pm 2.5$ \\
\hline SOT-6 & $37.5 \pm 7.5$ & $53.5 \pm 8.1^{*}$ & $37.5 \pm 7.9$ & $36.2 \pm 8.7$ & $16.0 \pm 2.1^{*}$ & $-1.3 \pm 2.2$ \\
\hline
\end{tabular}

Values are presented as mean \pm standard deviation. EX, Experimental group; CONT, Control group. ${ }^{*} \mathrm{p}<0.05$.

Table 3. Sensory analysis ratio of sensory organization test (SOT) before and after training

\begin{tabular}{|c|c|c|c|c|c|c|}
\hline \multirow[b]{2}{*}{ Sensory ratio (\%) } & \multicolumn{2}{|c|}{ Experimental group } & \multicolumn{2}{|c|}{ Control group } & \multicolumn{2}{|c|}{ Change values } \\
\hline & Pre-test & Post-test & Pre-test & Post-test & $\begin{array}{c}\text { EX } \\
\text { Post-pre }\end{array}$ & $\begin{array}{l}\text { CONT } \\
\text { Post-pre }\end{array}$ \\
\hline SOM & $96.3 \pm 4.1$ & $97.5 \pm 4.8$ & $93.5 \pm 5.5$ & $93.2 \pm 5.1$ & $1.2 \pm 2.7$ & $-0.3 \pm 2.3$ \\
\hline VIS & $76.7 \pm 4.5$ & $74.5 \pm 4.9$ & $85.6 \pm 6.3$ & $84.5 \pm 5.8$ & $-2.2 \pm 3.4$ & $-1.1 \pm 3.8$ \\
\hline VES* & $44.1 \pm 5.2$ & $61.4 \pm 5.8^{*}$ & $46.2 \pm 7.5$ & $45.8 \pm 8.6$ & $17.3 \pm 2.5^{*}$ & $-0.4 \pm 3.3$ \\
\hline PREF & $98.1 \pm 3.3$ & $99.2 \pm 3.6$ & $98.5 \pm 3.2$ & $98.2 \pm 3.3$ & $1.1 \pm 2.4$ & $-0.3 \pm 3.1$ \\
\hline
\end{tabular}

Values are presented as mean \pm standard deviation.

EX, Experimental group; CONT, Control group; SOM, Somatic ratio; VIS, Visual ratio; VES, Vestibular ratio; PREF, Visual preference ratio. ${ }^{*} \mathrm{p}<0.05$.

계측에 의한 연구를 수행하였으며 이제까지 이러한 시도는 드물었 다. 동적자세측정기검사에서 실험군은 SOT 조건 5,6 점수가 치료 후 에 유의한 향상이 있었으며 감각분석에서는 실험군이 전정비 항목 의 점수가 운동 전보다 유의하게 향상되었다. 이는 대표적인 가상현 실 운동프로그램인 Wii 운동 프로그램이 MS 환자들의 전정기능을 향상시키는 효과가 있음을 정량적으로 실증하는 결과였다.

일반적으로 정상인은 자신의 시각 정보에 주로 의존하여 평형을 유지하지만 조건 6에서처럼 시야가 혼란이 오는 등 잘못된 정보를 주 게 되면 시각에 대한 의존은 억제되고 체성감각이나 전정감각에서 얻은 정보에 더 의존하여 자세를 바로잡게 된다. 그러므로 조건 6에 서 개선이 있었던 것은 실험군의 중추신경계가 시각에서 정확한 정 보를 선택하는 능력이 치료 후에 개선되었음을 의미했다. 즉각적인 시각 되먹임을 부여하는 방법을 사용하여 훈련시키면 평형성을 개선 시킬 수 있다고 하는데 동작을 하는 동시에 자신의 동작을 관찰함으 로써 거울신경세포를 이용한 신경재활의 운동 재학습을 강화시킬 수 있기 때문이다. ${ }^{23}$ 이로 보아 실험군의 MS 환자들은, 시각 되먹이기 가 풍부한 게임기로 훈련을 받았기에 조건 6의 점수가 상승하였다고 생각된다.

감각분석에서 전정비의 점수가 향상되었던 것은 운동프로그램이 전정계에 대한 소뇌의 감독 조절 능력을 향상시켰다는 것을 의미한 다. 신경생리학적 관점에서 볼 때에 소뇌는 자세조절을 위한 되먹이
기 제어 및 감독하 학습에 주요 역할을 하고, 기저핵은 보상을 최대 화하기 위한 내향성의 되먹이기에 중요하다. 소뇌는 자세를 바로잡는 전정척수반사를 시행하기 위해 시각 전정감각, 체성감각 등 여러 감 각 정보들을 통합하는 중요 중추이다. 중추신경계에 병변이 있는 $\mathrm{MS}$ 환자들은 가상현실 속에서 운동을 하면서 소뇌가 시각 등의 되먹이 기를 많이 받게 되었고, 따라서 시각 및 전정감각의 정보를 통합하는 능력을 최대한 향상시킬 수 있도록 훈련되었을 것이다. 그렇게 해서 훈련을 통해 향상된 소뇌의 통합 능력은 뇌뿌리와 척수에도 영향을 줘서 자세조절에 개선을 가져왔을 것으로 생각된다. ${ }^{24}$

또한 가상현실 운동프로그램은 시각,청각, 고유감각의 되먹임을 결합한 감각성 신호들의 풍부한 환경을 제공하므로 환자는 가상현 실에 나타난 운동을 수행하면서 자신의 균형상태와 움직임 상태를 직접 보고 시각적, 청각적 피드백을 받아서 전정계로부터의 자극과 고유수용기의 자극을 강화할 수 있다. 게임에서 필요한 운동성에 더 많은 주의력과 집중력을 발휘하고 근력운동계, 눈돌림, 소뇌, 및 변연 계 회로들을 활용하여 신체의 균형능력을 향상시켰던 것으로 생각 된다. MS 환자의 균형 능력의 향상이 낙상을 예방하고 생활의 질을 개선시키는 데에 중요하다는 점을 상기한다면 본 연구에서 환자들의 동적자세측정기 검사결과의 개선을 보인 것에서 증명된바, 가상현실 을 통한 신체활동을 통해서도 균형능력의 향상을 가져올 수 있고 생 활의 질을 개선시킬 수 있다는 것을 보인 것으로 결론지을 수 있다. 
본 연구 결과는 뇌신경계 질환을 않고 있는 환자를 대상으로 한 가 상현실 운동프로그램의 효과에 대한 최근의 연구 보고들과 부합된 다. Hertz ${ }^{25}$ 는 파킨슨병 환자들에게 1 시간 동안 Wii 게임 중 균형발판 을 사용하지 않는 복싱이나 테니스 등 여러 가지 스포츠 가상현실 운 동을 주당 3 회씩 8 주간 시킨 후에 근경직, 운동능력들이 개선되고 우 울증의 치료 효과가 있었다고 보고하였다. 흥미롭게도 실험자의 $60 \%$ 는 실험이 끝난 후에도 Wii를 계속 사용하기 위하여 게임기를 구매하 기를 원하였다고 한다. Hertz 등 26 은 20명의 퇴행성 뇌질환 환자들에 게 4 주 동안 1 주에 3 회의 $\mathrm{Wii}$ 게임을 하게 한 후 시작 전보다 신체활동 도와, 운동 능력이 개선되고 우울감도 개선되는 경향을 관찰하여서 환자들의 삶의 질의 개선에 가상현실 운동치료가 효과적이었다고 하 였다. 그러나 게임을 1 달간 중단한 후에 다시 측정한 검사상에서는 실 험 시작 전 수준으로 다시 회귀되어 있어서, 가상현실 운동프로그램 도 다른 운동프로그램들과 마찬가지로 지속성이 중요하다고 하였다.

국내에서는 Kim과 $\mathrm{Kim}^{17}$ 의 연구에서 가상현실 실험군은 Berg 균 형 척도가 훈련 전 44.42 점에서 훈련 후 51.18점으로 증가함으로써 유 의한 차이를 나타내었다고 하였으며, 두 집단 간 비교에서도 실험군 이 대조군에 비하여 유의한 차이를 나타내었다고 하였다. 본 연구와 는 대상자 선정에서 차이가 있었지만 연구 결과는 유사하였다. Kim 등 27 은 낙상 위험이 많은 노인 인구에서 가상현실을 이용하여 느린 연속적 운동치료를 적용한 후에 균형 능력이 대조군에 비해 실험군 이 유의하게 증가하였다고 보고하였다. Lee 등 20 은 65세 이상 여성 노 인을 대상으로 가상현실 운동프로그램을 적용하였고 기능적 팔 뺃 기 검사 결과 그 정도가 통계학적으로 증가하는 결과를 관찰하였으 며, 트레드밀을 이용한 걷기 운동프로그램 집단에 비해 가상현실 운 동프로그램 집단에서 증가의 폭이 유의한 차이가 있었다고 하였다.

Lee 등 19 은 파킨슨병 환자들에게 가상현실 운동프로그램을 8 주간 적용한 실험에서 실험군이 훈련 후에 버그균형척도 및 기능적 뻗기 검사, 외발 기립 검사, 의자에서 일어나 걸어가기 검사 및 하지 근력 검 사 등에서 실험 전보다 통계학적으로 유의한 차이를 나타내었다고 하였다. 집단 간 비교에서도 온열치료까지만 실시한 대조군에 비해 실험군에서 통계학적으로 유의한 차이를 나타내었다고 하였다. 이것 은 본 연구에서와 같은 동적자세측정기 등을 사용한 정량적 검사가 아니고 주관적인 척도를 사용한 차이가 있고 대상자가 다르긴 하지 만 가상현실 프로그램이 신경계통 질환 환자들의 균형을 개선시키 는 효과를 보였다는 점에서 본 연구 결과와 일치하였다.

실험군에서 균형능력의 개선이 온 이유로써 게임형태의 가상현실 운동 프로그램이 줄 수 있는 다음과 같은 사회 정서적 이점들도 고려 할 수 있다. 첫째로, 게임기를 사용한 실험자들의 집중력이 상승한 것 을 들 수 있을 것이다. 가상현실 기반 운동 프로그램은 화면을 통해 받을 수 있는 시청각적 자극으로 대상자의 흥미를 끌고 운동의 지속
성과 집중력을 높일 수 있다. 두 번째로, 운동에 몰입한 환자는 게임 결과에 따른 점수를 더 얻고 싶어하는 경쟁심 및 성취의욕이 고취되 므로 보상회로(reward circuitry)를 활성화시켜서 위약효과에 의해 더 많은 증상의 개선이 올 수 있다. 셋째로, 게임을 통해서 스트레스 및 불안 걱정 등이 해소됨을 들 수 있다. 심한 불안감은 평형에도 악영향 을 끼칠 수 있으므로 즐거운 게임을 가족들과 함께함으로써 불안감 해소에 도움이 될 수 있다. 본 연구에서 운동이 끝난 후 $53 \%$ 의 환자들 은 Wii 시스템으로 운동을 지속하고 싶어 하였다. 이는 선행연구에서 8 주의 운동 후에 $60 \%$ 가 자택에서 사용하기 위해 구입하고 싶어 하였 다는 $\mathrm{Hertz}^{25}$ 의 보고와 유사하였다.

상기의 선행 연구들에서와 같이 본 연구에서도 가상현실 운동 프 로그램은 MS 환자의 균형 능력 향상이라는 효과를 미칠 수 있음을 동적자세측정기를 사용하여 정량적으로 실증해 보였다. 장소를 많 이 차지하지 않으면서 저렴하고 가정과 병원에서 이동과 설치가 손쉬 운데다가 가상현실이라는 흥미 고취로 인하여 환자의 동기 부여를 이끌어 낼 수 있는 이점이 있는 이 프로그램은 향후 MS 등 뇌신경계 질환 환자들의 물리치료에 적용할 수 있도록 더 많은 연구가 필요할 것이다.

본 연구의 문제점으로는 첫째, 실험군의 숫자가 충분히 크지 않았 다는 점이다. 두 번째는 실험 기간이 비교적 짧았다는 점이며, 마지막 으로 대상군을 정할 때에 비교적 증상이 심하지 않은 환자를 대상으 로 하고 중증의 환자들은 제외되었다는 점이다. 본 연구의 미래 효용 성으로 고려될 수 있는 점으로는, 현재 우리나라에서는 인터넷의 광 범위한 보급으로 도서벽지의 주민들을 대상으로 한 원격 의료가 관 심을 끌기 시작하고 있는바, 전자정보산업의 발달로 가상현실을 적 용할 수 있는 분야가 확장되고 있는 추세에 맞추어 환자 치료에 가상 현실 프로그램이 치료수단으로 활용 될 수 있다는 것이다. 선진국에 서는 가상현실을 활용한 의료기술과 운동 치료법의 개발에 박차를 가하고 있는 실정이므로 향후 우리나라에서도 쉽게 사용 가능하고 더 효율이 높은 가상현실 기반 운동기기와 운동 치료 방법을 개발하 고수출할 수 있다면 국가 경쟁력 상승에도 기여할 수 있을 것으로 기 대된다.

\section{ACKNOWLEDGEMENTS}

이 논문은 2014년도 단국대학교 대학연구비의 지원으로 연구되었음.

\section{REFERENCES}

1. O' Sullivan SB. Multiple Sclerosis. In: O'Sullivan SB, Schmitz TJ, eds. Physical Rehabilitation: Assessment and Treatment. Philadelphia, Pa, FA Davis, 2001:715-46. 
2. Weinshenker BG. Natural history of multiple sclerosis. Ann Neurol. 1994;36(suppl):S6-S11.

3. Cheong HK, Lee KH, Kim BJ, et al. Nationwide survey of multiple sclerosis in Korea. The Report of National Institute of Health. 2006;43:32021.

4. Cattaneo D, Jonsdottir J. Sensory impairments in quiet standing in subjects with multiple sclerosis. Mult Scler. 2009;15:59-67.

5. Finlayson ML, Peterson EW, Cho CC. Risk factors for falling among people aged 45 to 90 years with multiple sclerosis. Arch Phys Med Rehabil. 2006;87:1274-9.

6. Matsuda PN, Shumway-Cook A, Bamer AM, et al. Falls in multiple sclerosis. PM\&R. 2011;3:624-32.

7. DeBolt LS, McCubbin JA. The effects of home-based resistance exercise on balance, power, and mobility in adults with multiple sclerosis. Arch Phys Med Rehabil. 2004;85:290-7.

8. Todd J. Physiotherapy and multiple sclerosis. In: Capildeo R, Maxwell A, eds. Progress in Multiple Sclerosis. Hong Kong, Macmillan Press, 1983: 31-44.

9. Sveistrup H. Motor rehabilitation using virtual reality. J Neuroeng Rehabil. 2004;1(1):10.

10. Steuer J. Defining virtual reality: Dimensions determining telepresence. J Commun. 1992;42(4):73-93.

11. Rizzo AA, Buckwalter JG. Virtual reality and cognitive assessment and rehabilitation: The state of the art. Stud Health Technol Inform. 1997;44: 123-45.

12. Weiss PL, Rand D, Katz N, et al. Video capture virtual reality as a flexible and effective rehabilitation tool. J Neuroeng Rehabil. 2004;1(1):12.

13. Rizzo AA, Buckwalter JG, Bowerly T, et al. The virtual classroom: A virtual reality environment for the assessment and rehabilitation of attention deficits. Cyberpsychol Behav. 2000;3:483-99.

14. Stevenson IH, Fernandes HL, Vilares I, et al. Bayesian integration and non-linear feedback control in a full-body motor task. PLoS Comput Biol. 2009;5:e1000629.

15. Clark RA, Bryant AL, Pua Y, et al. Validity and reliability of the Nintendo
Wii Balance Board for assessment of standing balance. Gait Posture. 2010;31:307-10.

16. Maclean N, Pound P, Wolfe C, et al. Qualitative analysis of stroke patients' motivation for rehabilitation. BMJ. 2000;28:1051-4.

17. Kim JH, Kim CS. Effects of virtual reality program on standing balance in chronic stroke patients. J Kor Phys Ther. 2005;17(3):351-67.

18. Chung JH. The Effect of training using virtual reality system on sitting balance and activities of daily living for the patient with spinal cord injury. J Kor Phys Ther. 2009;21(2):31-8.

19. Lee DK, Kim EK, Kim YN, et al. Effects of virtual reality training program on balance and lower muscular strength of Parkinson's disease patients. J Kor Phys Ther. 2013; 25(2):96-102.

20. Lee JH, Park SU, Kang JI, et al. Effects of virtual reality exercise program on muscle activity and balance abilities in elderly women. J Kor Phys Ther. 2011;23(4):37-44.

21. Kurtzke JF. Rating neurological impairment in multiple sclerosis: An expanded disability status scale (EDSS). Neurology. 1983;33:1444-52.

22. Nashner LM. Computerized dynamic posturography. In: Goebel JA, eds. Practical management of the dizzy patient. Philadelphia, PA, Lippincott Williams \& Wilkins, 2001;143-70.

23. Buccino G, Gatti R, Giusti MC, et al. Action observation treatment improves autonomy in daily activities in Parkinson's disease patients: Results from a pilot study. Mov Disord. 2011;26(10):1963-4.

24. Ioffe ME, Chernikova LA, Ustinova KI. Role of cerebellum in learning postural tasks. Cerebellum. 2007;6:24-37.

25. Hertz NB. The wii and Occupational therapy. Occup Ther Pract. 2009; 14(7):19-25.

26. Hertz NB, Mehta SH, Sethi KD, et al. Nintendo Wii rehabilitation ("Wiihab") provides benefits in Parkinson's disease. Parkinsonism Relat Disord. 2013;19:1039-42.

27. Kim JJ, Gu S, Lee JJ, et al. The effects of virtual reality-based continuous slow exercise on factors for falls in the elderly. J Kor Phys Ther. 2012; 24(2):90-7. 